\title{
Approaches to Enhance the Biodegradation of Polyolefins
}

\author{
Ambika Arkatkar ${ }^{1}$, J. Arutchelvi ${ }^{1}$, M. Sudhakar ${ }^{1}$, Sumit Bhaduri ${ }^{2}$, Parasu Veera Uppara ${ }^{2}$ and \\ Mukesh Doble ${ }^{1, *}$
}

\author{
${ }^{I}$ Department of Biotechnology, Indian Institute of Technology Madras, Chennai, 600036, India \\ ${ }^{2}$ Polymer Research and Technology center, Reliance Industries Limited, V.N. PuravMarg, Mumbai-600071, India
}

\begin{abstract}
Accumulation of non-biodegradable plastics leads to increase in land and water pollution. Polyolefins including polyethylene and polypropylene are the major plastics to be dumped in the environment and due to their recalcitrant nature persist in the environment. The hydrophobicity, high molecular weight, chemical and structural composition of these polymers hinders their biodegradation. In this review current research that have been performed to understand the abiotic mechanism of the degradation process, and various physical, chemical and biochemical approaches that can be adopted to enhance their biodegradation are discussed. Genetic engineering approaches to enhance the performance of the microorganism or computational techniques to simulate the degradation pathways could be the future to speed up the degradation of these polymers.
\end{abstract}

Keywords: Polyolefins, Biodegradation, Pretreatment, Biosurfactants.

\section{INTRODUCTION}

Synthetic polymers have become technologically important since 1940s subsequently replacing glass, wood, masonry and other constructional materials, and even metals in many industrial, domestic, commercial and environmental applications. These widespread applications are not only due to their favourable mechanical and thermal properties but also due to their stability and durability. These endless applications of the polyolefins have subsequently resulted in the formation of large quantities of waste, leading to their dumping in the environment. The increased cost of solid waste disposal as well as potential hazards associated from waste incineration has lead to serious concern [1]. In addition, plastic waste affects the flora, fauna and animals in the biosphere.

Non-biodegradable plastics accumulate in the environment at a rate of 25 million tons per year [2]. Polypropylene (PP) and Polyethylene which includes low density polyethylene (LDPE) and high density polyethylene (HDPE) represent 18.4 and $37.7 \%$ respectively of the total polymers sales in the year 2004 in United States, Canada and Mexico and hence it could be concluded that more than $50 \%$ of plastic waste could be polyolefins [3,4]. This review investigates the various reported approaches that could be adopted to enhance the biodegradation of polyolefins. This degradation could be due to a synergy between the environmental factors and microbes which utilise this polymer as a carbon source. All these three polymers have, although the same repeat units have different chain branching, arrangement and packing density leading to differences in their properties.

*Address correspondence to this author at the Department of Biotechnology, IIT Madras, Chennai-600036, India; Tel (O):+9144-22574107; Fax: +914422574102; E-mail: mukeshd@iitm.ac.in

\subsection{Biodegradation}

Biodegradation is defined as a process which occurs due to the action of enzymes that are secreted by living organisms (bacteria, fungi etc.) leading to its chemical decomposition. Primary biodegradability depends upon the formation of biofilm, which is defined as a layer of deposition of the microorganisms and their secreted polysaccharides etc on the polymer surface. This is followed by the breakdown of the polymer to low molecular weight oligomers (probably due to the enzymes that are secreted by the microorganisms) and then they are easily assimilated by the microbes. The ultimate degradation leads to the formation of $\mathrm{CO}_{2}$ and water. The prerequisite for this process to take place is that the microorganism should be able to use the polymer as its sole carbon source.

In natural conditions, the degradation of plastics is a very slow process and it is a function of environmental factors such as temperature, humidity of air and moisture in the polymer, $\mathrm{pH}$ and solar energy; polymer properties and biochemical factors. The most problematic plastics are polyolefins as they are resistant to microbial attack, due to the absence of any active functional groups.

Factors affecting the rate of biodegradation of polyolefins include the following [5].

1. Lack of active functional group

2. Highly hydrophophic nature

3. High molecular weight

4. Physical form (films, pellets, powder or fibers)

5. Distribution of crystalline and amorphous regions

6. Structure of the polymer(linear chain or branching) 


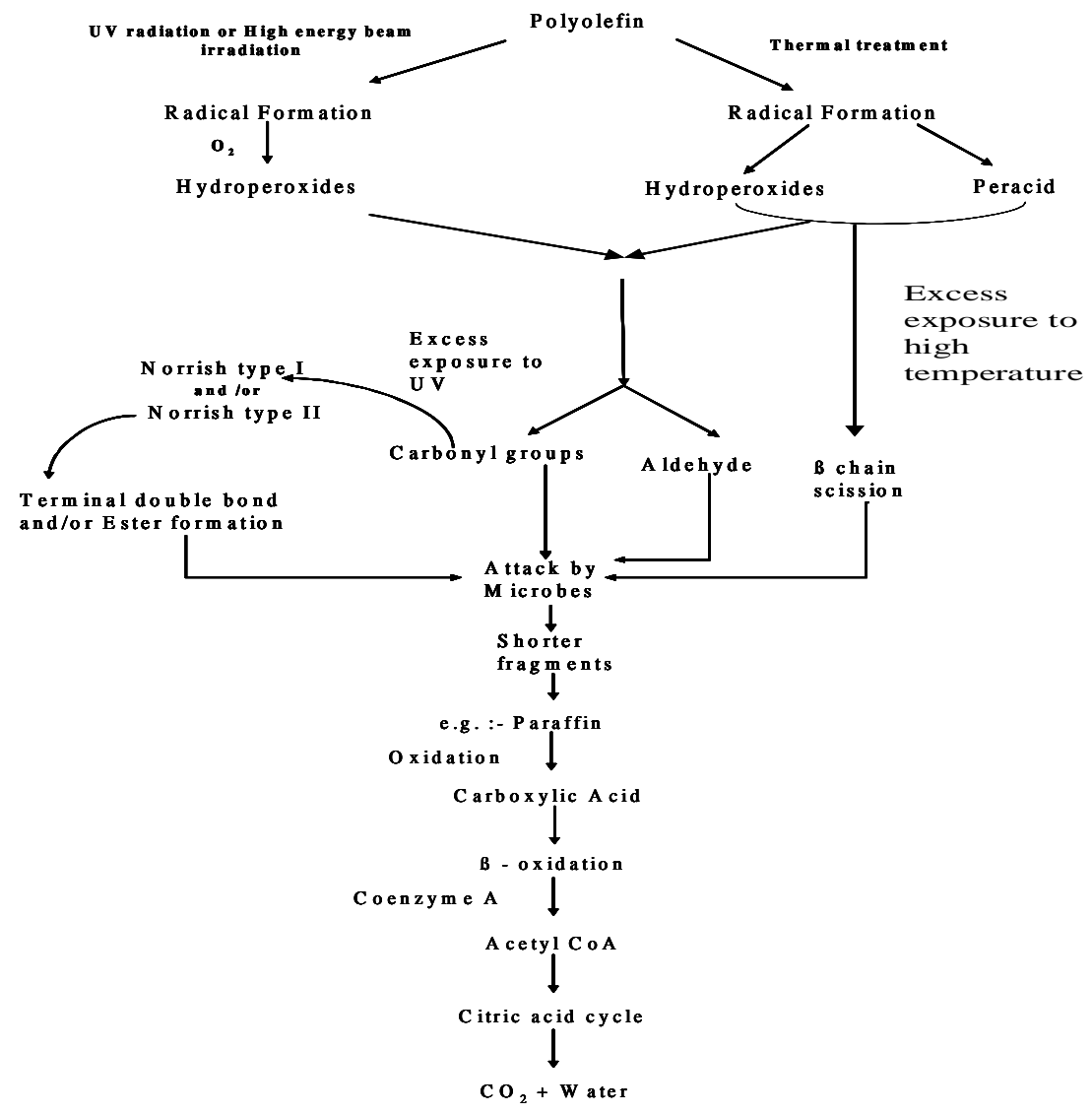

Fig. (1). General Mechanism of Polyolefin biodegradation. [5, 11-17].

7. Chemical composition of the polymer (blends, presence of additives, UV stabilizers, and antioxidants etc.)

8. Microorganisms in the form of mixed culture present in environment

9. Properties of microorganism including their ability to produce biosurfactant or other exo polysaccharides, hydrophobic nature of bacterial cell wall etc.

\subsection{Mechanisms of Polyolefin Biodegradation}

Polyolefins consist of repeating methylene units in case of HDPE, methylene and methyne units in case of LDPE and in case of PP there are methylene and methyne group per repeating unit, with an extremely high molecular weight, typically several hundreds or thousands of daltons. Additives used for the stabilization of the polymer further slow down the rate of degradation. In addition, branching increases the packing of the chains preventing the approach of the microorganism. One more factor which contributes to its slow biodegradation of plastic is lack of its water solubility. The size of the polymer molecule is large; hence the microorganism is unable to transport it directly into the cells.

Few reports have been published that elucidate the mechanism of biodegradation of polyolefins. The mechanism of photodegradation of polyethylene followed by its biodegradation has been proposed and verified. During photooxidation, cleavage occurs predominantly at the weak links which have lower bond energies (for example $\mathrm{C}-\mathrm{H}$ has bond energy of $98 \mathrm{Kcal} / \mathrm{mole}$ and $\mathrm{C}-\mathrm{O}$ has bond energy of 79
$\mathrm{Kcal} / \mathrm{mole}$ ) [6]. This leads to the formation of free radicals. The cleavage can occur not only due to its exposure to UVradiation, but also due to heat, ionising radiation and mechanical stresses. The radicals that are generated can react further with atmospheric oxygen and trigger the oxidation of the polymer. This reaction continues in a stepwise fashion producing carbonyls, aldehydes, peracid and acids [7-10]. (Fig. 1) (Please insert Fig. 1) The carbonyl group, if exposed again to UV, can follow Norrish type I and/or Norrish type II reaction to generate terminal double bond or ester group [5, $11,12,18]$ (Fig. 1). In the case of biodegradation, microorganisms can assimilate these abiotic intermediates, thus complicating the degradation products found in the environment. The rate of degradation is sensitive to microbial population, moisture, temperature, and oxygen in the environment $[19,20]$.

Biodegradation of polyethylene is expected to be similar to that of paraffins, and it has been well documented. The biodegradation of the latter starts with the oxidation of the alkane chain to a carboxylic acid, which latter undergoes $\beta$ oxidation. The mechanism of the biodegradation of polyethylene shows similarities with the $\beta$-oxidation of fatty acids and paraffin's in man and in animals [11]. The initial abiotic step involves the oxidation of the polymer chain, which leads to the formation of carbonyl groups. During microbial assimilation, a decrease in carbonyl groups is noted. The carboxylic acids formed react with coenzyme A $(\mathrm{CoA})$ to remove two carbon fragments, acetyl-CoA. This latter is metabolized in the citric acid cycle to produce carbon dioxide and water as the final degradation products [3]. Photo- 
oxidation enhances the rate of biodegradation of the polymer. It leads to the scission of the main chain in the polymer, thereby leading to the formation of low molecular weight products. This results in the generation of large surface area due to its embrittlement and also a greater degree of hydrophillicity due to the introduction of carbonyl groups. All these factors further promote the biodegradation of the polymer.

\section{ENHANCEMENT OF BIODEGRADATON OF POLYOLEFIN}

Efforts have been made to enhance the rate of biodegradation of these recalcitrant polymers by modifying the polymer or initiating the degradation process by generating free radicals etc. The rate of the biodegradation can be enhanced by

(1) Blending them with biodegradable natural polymers including starch or cellulose, or with biodegradable synthetic polymers including poly lactic acid (PLA), polycaprolactum (PCL).

(2) Mixing with prooxidants.

(3) Carrying out pretreatment which includes thermal, $\mathrm{UV}$, microwave, high energy radiation and chemicals.

(4) Isolating and growing micro organisms that can efficiently degrade these polymers or

(5) Improving the attachment of the organisms on the recalcitrant polymer surface. This can be achieved by using surface active agents or inducing the microorganism to produce surfactant and

(6) Through genetic modification of the microorganism.

All these approaches will be discussed in the subsequent sections with relevant examples.

\subsection{Polymer Blends}

\subsubsection{Polyolefin with Natural Polymer}

Blending of natural polymer with synthetic one is a strategy to enhance biodegradation. The natural polymers include starch, cellulose, chitin etc. The percentage of natural polymer added in the blend affects the physical and mechanical properties of the synthetic polymer. Shelf life of such blends decrease since the rate of degradation of the natural polymer used as filler is several orders of magnitude larger than that of the synthetic polymer.

The final properties of the blend depend on the

1. Kind and amount of blend material that is added

2. Its morphology

3. Interaction between the blend material and the polymer

4. Crystalline nature of the polymer

5. Preparation and processing conditions for the blends [21]

Starch provides higher oxygen permeability as it is consumed by microorganisms. Higher permeability helps in the release of degradation products from the sample, thus making the matrix hollow, increasing the surface to volume ratio [22]. Presence of any biodegradable polymer as a blend will affect the behaviour of the polyolefins in outdoor weathering and will act as an initiator for their oxidative degradation by heat, light and microbes. Biodegradation of polyolefincellulose and polyolefin-starch blends have been reported using soil organism and soil compost [23, 24]. It is found that polyethylene-cellulose blend having $5 \%$ to $15 \%$ of cellulose fails to show any significant increase in biodegradation, whereas when the amount of cellulose is increased up to $30 \%$ the degradation of the blends started after 14 weeks under composing conditions [21]. The increasing cellulose amount in the polymer affects its physical property considerably making it unsuitable in many applications. Mucor rawxii is able to reduce the tensile strength of thermally pretreated (for 10 days at $70{ }^{\circ} \mathrm{C}$ ) polyethylene containing $6 \%$ starch by $60 \%$ while Streptomyces species reduced the percentage elongation of the same blend from $46.5 \%$ to $28.5 \%$ [24]. Starch or cellulose present in the blends is easily degraded by the organism leaving behind the polymer [7, 16, 20]. These carbohydrates or fillers increase the adhesion of the organisms to the surface of the polymer due to the hydrophillic nature of the blend material. The adhesion of the organisms also improves its interaction with the hydrophobic polymer. The fungus Phanerochaete chyrosporium shows increase in the degradation of polyethylene-lignin and polypropylene-lignin blends (containing 10-30\% of lignin) with increase in the lignin component. Biotransformation of lignin initiates its biodegradation and facilitates the attack of microbes. The hydroxyl radicals initiate the lignin degradation as well as destruction of the rigid polyolefin matrix [25].

Experiments conducted by us with marine microorganisms (Bacillus sphericus GC subgroup IV (Alt), Bacillus cereus subgroup A (BF20)), under in vitro conditions, in mineral salt medium at $180 \mathrm{rpm}$ shaking, and at $28-37^{\circ} \mathrm{C}$ (Fig. 2) show that the rate of biodegradation of starch blended polyethylene is high when compared to the unblended pure polymer ( $15 \%$ and $11 \%$ weight loss of the former and the later respectively in six months) [26]. The \% weight loss is the difference between the initial and final gravimetric weight of the dried film.

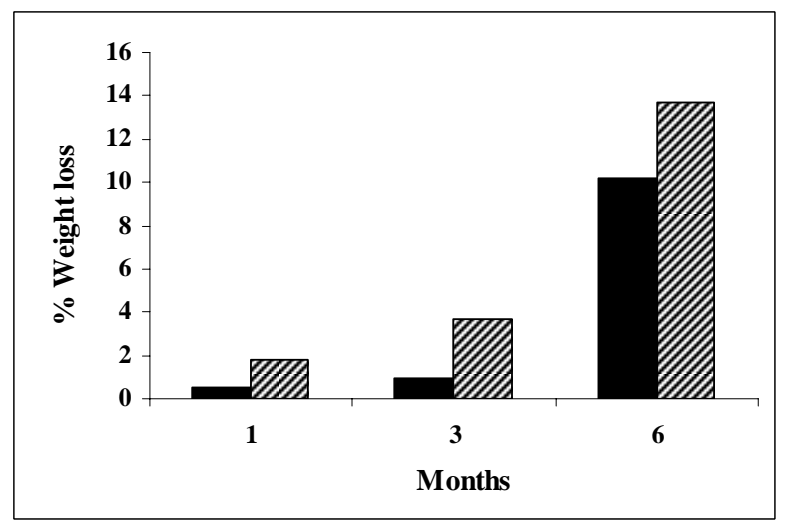

Fig. (2). Unblended Low Density Polyethylene ( $\square$ ) and starch blend Low Density Polyethylene treated (ש) with Bacillus sphericus [26]. 


$$
\left[\mathrm{L}_{3},(\mathrm{RCOO})_{3} \mathrm{Fe}^{\mathrm{III}}\right] \stackrel{\mathrm{h} v}{\longrightarrow}\left[\mathrm{L}_{4},(\mathrm{RCOO})_{2} \mathrm{Fe}^{\mathrm{II}}\right]+\mathrm{RCOO} \longrightarrow \stackrel{\bullet}{\mathrm{R}}+\mathrm{CO}_{2}
$$

Fig. (3). Oxidation of polyolefins in the presence of $\mathrm{Fe}^{\mathrm{III}}$ as prooxidant ( $\mathrm{L}=$ suitable ligand). [29]

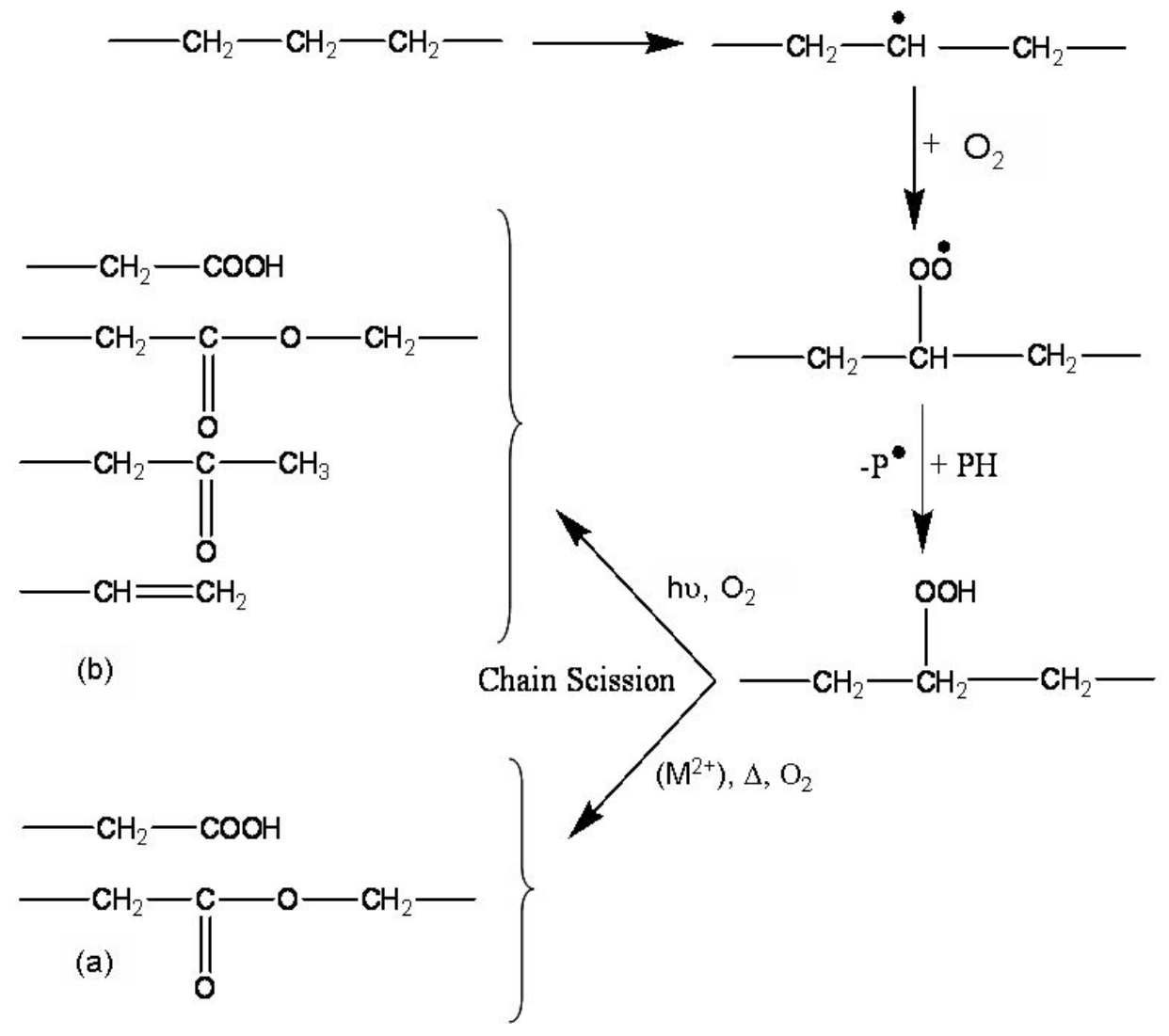

Fig. (4). Comparison of oxidation of polyolefins in the (a) presence and (b) absence of prooxidants $\left(\mathrm{PH}=\right.$ polymer chain, $\left(\mathrm{Mn}{ }^{2+}-\mathrm{Manga-}\right.$ nese transition metal ion and $\Delta$ - heat supplied) [29].

\subsubsection{Polyolefin and Biodegradable Polymer Blends}

Biodegradable plastics as a packaging material has recently drawn considerable attention since they could be disposed in the environment without creating long term waste disposal problems. Number of successful approaches has been adopted to arrive at degradable polymer blends which would retain the desired physical, mechanical and chemical properties of the original polymer but at the same time have higher biodegradation rates in the environment than the unblended ones. Copolymers of ethylene and styrene with vinyl ketone (methyl vinyl ketone) are being promoted as photodegradable plastics [19]. Poly lactic acids (PLA) and poly caprolactone (PCL), two common biodegradable polymers are also used as blending material. These reduce the hydrophobic nature of polyolefins. The main issue that needs to be addressed during the preparation of these blends is the poor miscibility of PCL and PLA in polyethylene and polypropylene. Use of compatibilizers leads to good miscibility. 80:20 blend of PCL and PE show enhanced fungal growth and the consortia include Aspergillus niger, Penicillium funiculosum, Chaetomium globosum, Gliocladium virens and Aureobasidium pullulans. The amorphous region of the blend which is contributed by PCL is reduced in the 16 weeks [27]. Blends of LDPE-PCL and PP-PCL when reacted with partially purified lipase enzyme from Rhizopus arrhizus show a high level of biodegradability, up to $70 \%$ for LDPE and $60 \%$ for PP. The PCL content in the blend is degraded whereas LDPE and PP polymers in the blend remained unchanged [28]. Lipase being an esterase is able to cleave the $\mathrm{C}-\mathrm{O}$ bond present in PCL but is not able to break the $\mathrm{C}-\mathrm{C}$ bond present in polyolefins.

\subsection{Polyolefin with Prooxidant}

Another approach to increase the rate of biodegradation of the polymer is by adding additives such as prooxidants, which will accelerate photo and thermal oxidation in the chain. Prooxidants are generally transition metals including $\mathrm{Fe}, \mathrm{Co}$, and $\mathrm{Mn}$ which are added in the form of stearates. The metal ions such as $\mathrm{Fe}^{3+}$ initiates the formation of radical during the photo-oxidation (Fig. 3), whereas $\mathrm{Co}^{2+}$ or $\mathrm{Mn}^{3+}$ in the absence of light act as catalyst for the decomposition of peroxides leading to chain scission (Fig. 4). [29] The prooxidant and molecular oxygen are present mostly in the amorphous region of the polymer and hence the oxidation pre- 


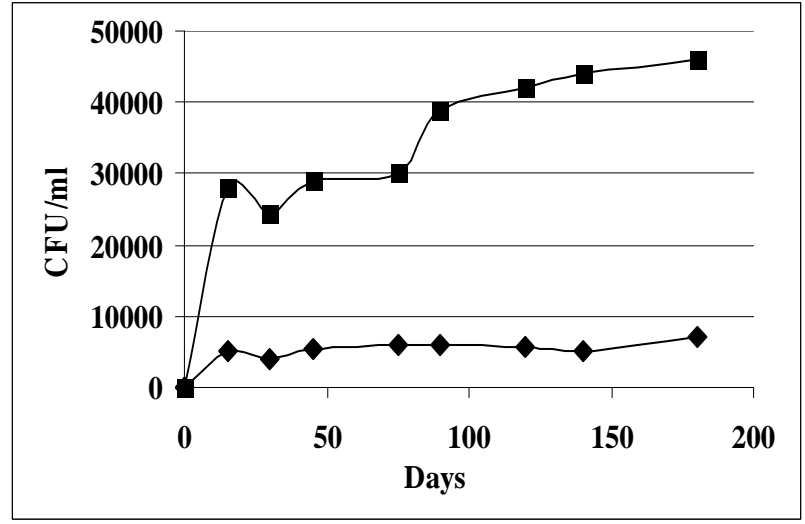

(a)

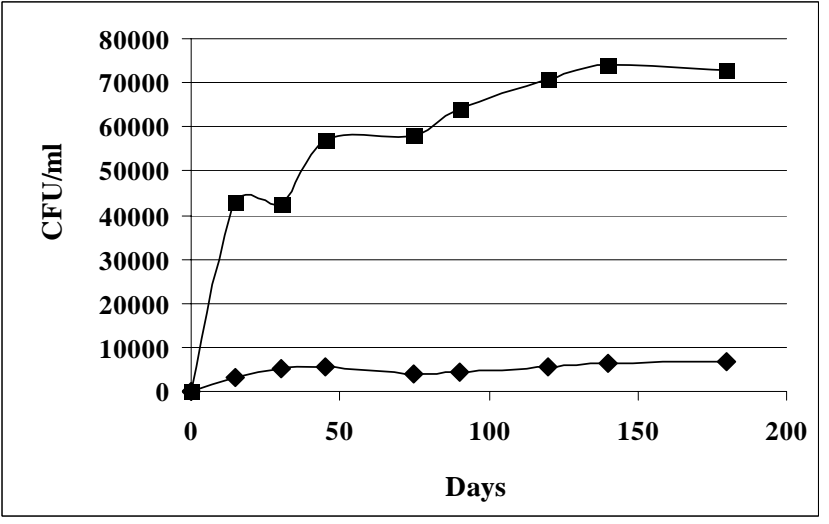

(b)

Fig. (5). Growth curve of marine bacteria in mineral salt medium in the presence of (a) Untreated ( $\bullet$ ) and thermally pretreated (घ) Low Density Polyethylene, (b) Untreated ( ) and thermally pretreated (ם) High Density Polyethylene. (CFU/ml- Colony forming units of bacteria/ milliliter of media) [26].

dominantly takes place there and leaves the crystalline region intact [8]. Materials with time programmed mechanical properties can be prepared by using a balanced mixture of antioxidant and prooxidant additives. During exposure to the weather when the antioxidant capacity is used up then there will be a relatively fast loss of mechanical properties of the polymer due to the presence of prooxidant leading to its fragmentation [30]. Thermally pretreated LDPE films containing prooxidants show $60 \%$ mineralization (based on $\mathrm{CO}_{2}$ production) in six months during composting leading to a drop of $5000 \mathrm{Da}$ in molecular weight [1]. Microbes R.rhodochrous and N.asteraides are reported to form biofilm on the thermal and photo oxidised LDPE and HDPE films containing prooxidant. In 200 days the films loose $50 \%$ of their mechanical strength. The NMR spectroscopic analysis of the supernatant after biodegradation revealed the presence of ethanol and formate which are the oxidation end-products of PE [31]. 48\% degraded fragments were extracted in boiling acetone from thermally pretreated LDPE films containing prooxidant after 100 days in river water [32]. While studying the effect of different degradation conditions on the oxidative degradation of polyethylene films with prooxidant as an additive it was found that the carbonyl index and molecular weight were affected by the experimental temperature and relative humidity [33].

\subsection{Pretreatments}

Pretreatment of the polymer using physical or chemical methods prior to biodegradation have been found to enhance the process considerably. The various treatment techniques are explained below with examples

\subsubsection{Physical}

\subsubsection{1. $U V$}

Sunlight is a rich source of UV radiation and polymer waste dumped in the open undergo this photo initiation process. Photo oxidation is controlled by the intensity of the light and it leads to the formation of radicals. These radicals propagate forming further radicals in the polymer thereby increasing its reactivity. This pretreatment leads to a decrease in the weight average molecular weight of the poly- mer. Cleaved chains are most frequently terminated by carboxylic groups and other functionalities such as esters, ketones, alcohols and double bonds. Peroxides and hydroperoxides which absorb UV weakly in the wavelength range of 290 to $400 \mathrm{~nm}$ play an important role in the photoinitiation, leading to the homolytic cleavage of the chain [34]. UV irradiation for $60 \mathrm{hrs}$. LDPE showed a weight loss of $6.2 \%$ as compare to untreated LDPE with Bravebacillus.brostelensis for 30 days [35]. UV irradiation increased the biodegradation by $25 \%$. UV irradiation of polyethylene for $500 \mathrm{hrs}$ enhances the growth of Penicillium simlicissimum YK [36].

\subsubsection{Thermal}

Thermal pretreatment makes the polymer more potent to microbial attack. As mentioned earlier in the mechanism of biodegradation, thermal treatment oxidises the chain there by introducing hydroxyl, carboxyl and hydroperoxyl groups. Formation of oxidised products also makes the polymer more hydrophilic which is more conducive for the attachment of the organism. Studies carried out in our laboratory exemplify the advantages of thermal oxidation on the extent of biodegradation of polyethylene and polypropylene [26, 37]. Thermally treated LDPE at $150^{\circ} \mathrm{C}$ for $120 \mathrm{hrs}$. showed increase in carbonyl index by $23 \%$ and when treated with fungi Phanerochaete chrysosporium showed increase in double bond index in three months indicating chain size reduction [38].

Marine strains namely Bacillus sphericus GC subgroup IV (Alt), Bacillus cereus subgroup A (BF20), Brevundimonas vesicularies (BF10) and Curtobacterium flaccumfaciens (BF12) utilise LDPE and HDPE films in mineral salt medium under in vitro conditions as carbon source [26]. Prior to exposure to the microbial culture, LDPE and HDPE are thermally pretreated at $80^{\circ} \mathrm{C}$ for 10 days. Fig. 5 (a) and (b) show the growth in terms of colony forming unit per milliliter $(\mathrm{CFU} / \mathrm{ml})$ based on serial dilution and spread plate technique of Alt on untreated and thermally pretreated LDPE and HDPE films. In both the cases it is seen that the growth of organism is 4 to 7 times higher in thermally pretreated when compared to untreated polymer. A decrease in percentage crystallinity is observed in both the polymers after they 


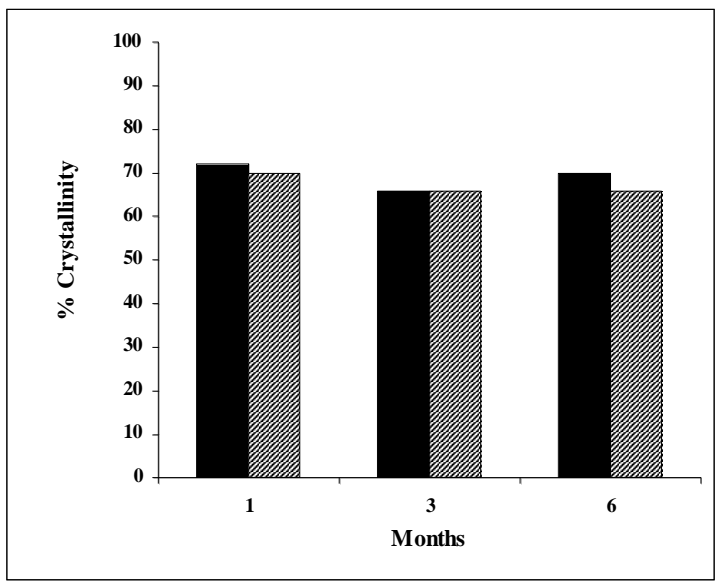

(a)

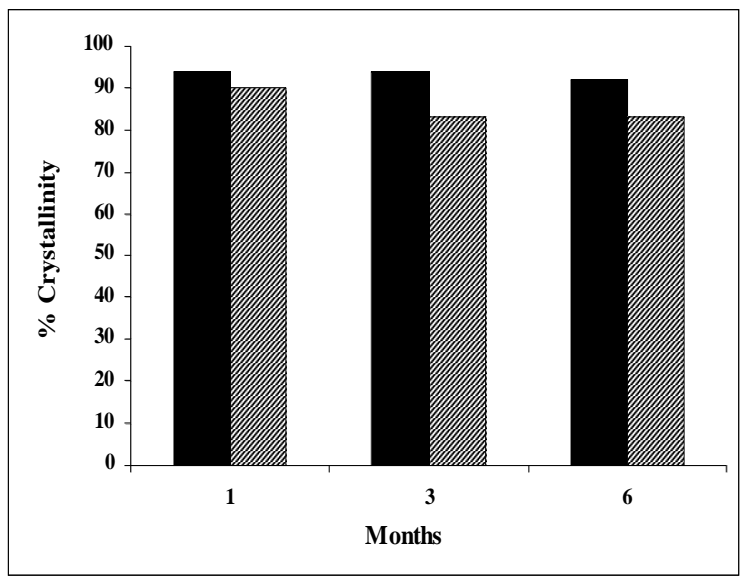

(b)

Fig. (6). Effect of pretreatment on percentage crystallinity of (a) Untreated ( $\square$ ) and thermally pretreated ( $\mathbb{\text { a }}$ ) Low Density Polyethylene, (b) Untreated $(\square)$ and thermally pretreated $(\mathbb{Z})$ High Density Polyethylene [26].

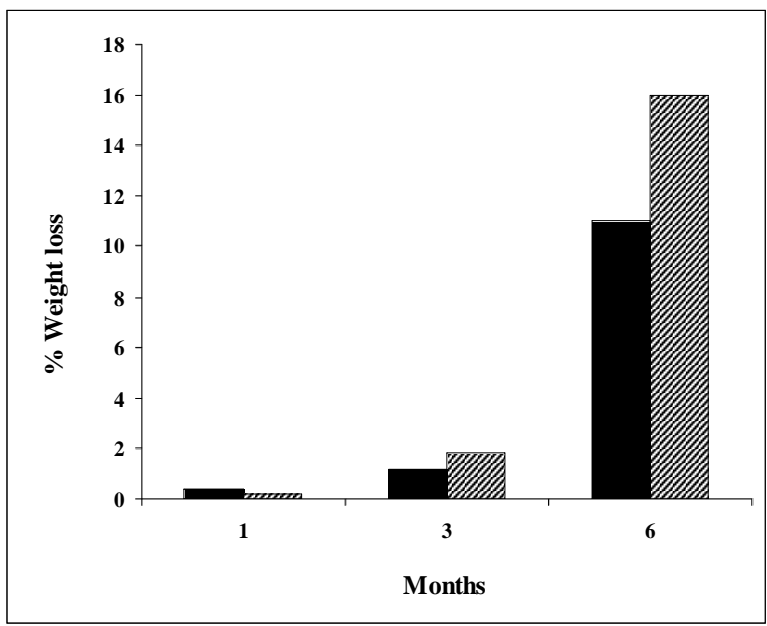

(a)

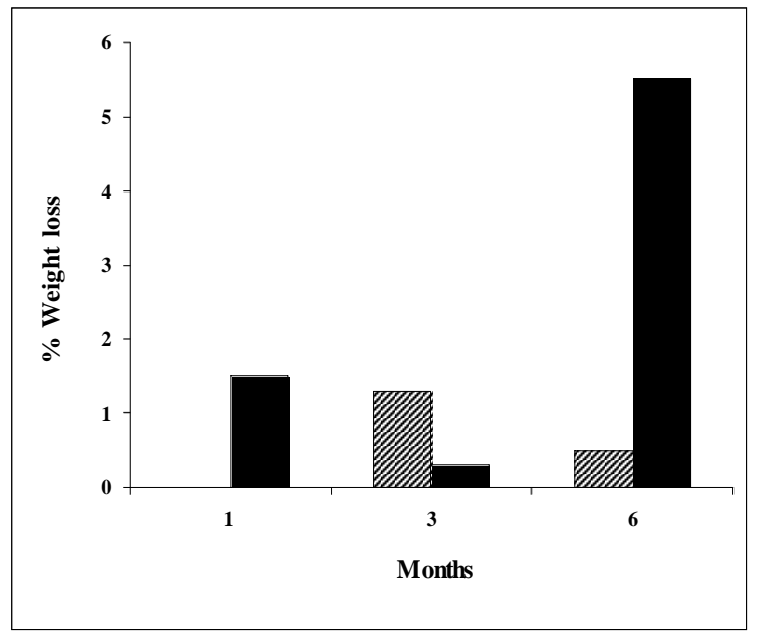

(b)

Fig. (7). Effect of pretreatment on percentage weight loss (a) Untreated ( $\square$ ) and thermally pretreated ( $\mathbb{A}$ ) Low Density Polyethylene, (b) Untreated ( $\square$ ) and thermally pretreated $(\mathbb{Q}$ ) High Density Polyethylene [26].

are exposed to marine microorganism B. sphericus and this decrease over a six month period is higher with thermally pretreated polymers as shown in Fig. 6 (a) and (b) [26]. A $17 \%$ weight loss with was observed with thermally pretreated LDPE in six months, while the weight loss was only $10 \%$ with untreated LDPE (Fig. 7 (a)). Similarly the weight loss was $5.5 \%$ and $1 \%$ with thermally pretreated and untreated HDPE samples respectively in six months (Fig. 7 (b)). (Please insert Fig. 5 ( $a$ and b), 6 ( $a$ and b), 7 ( $a$ and $a b)$ ) Experiments conducted in our lab showed that thermally pretreated pure polypropylene (PP) showed $7.1 \%$ and $10.1 \%$ weight loss in six and twelve months respectively, while untreated PP showed a weight loss of only $0.42 \%$ in 12 months with mixed soil microorganism [37] (Fig. 8). (Please insert Fig. 8). The experiment is performed in mineral salt medium at $180 \mathrm{rpm}$ shaking, and $28-37^{\circ} \mathrm{C}$. The $\%$ weight loss was measured as the difference between initial and final gravimetric weight of the films. Colony forming unit of the bacteria per milliter of media was calculated by serial dilu- tion and spread plating technique on nutrient agar plates. $\%$ Crystallinity was calculated from Fourier transform absorbance spectra (FTIR) of the polymer sample. Following formula was used to calculate \% crystallinity. [26]

$$
\% \text { crystallinity }=100-\left[\frac{\left[1-\frac{I_{a}}{1.233 I_{b}}\right]}{1+\frac{I_{a}}{I_{b}}}\right] 100
$$

where $I_{a}$ and $I_{b}$ are absorbance values from the bands at 1474 and $1464 \mathrm{~cm}^{-1}$ or at 730 and $720 \mathrm{~cm}^{-1} 1$, respectively.

All these studies clearly indicate that thermal pretreatment enhances biodegradation of polyolefins considerably. But the temperature and duration needs to be optimized for each polymer to achieve best results. 


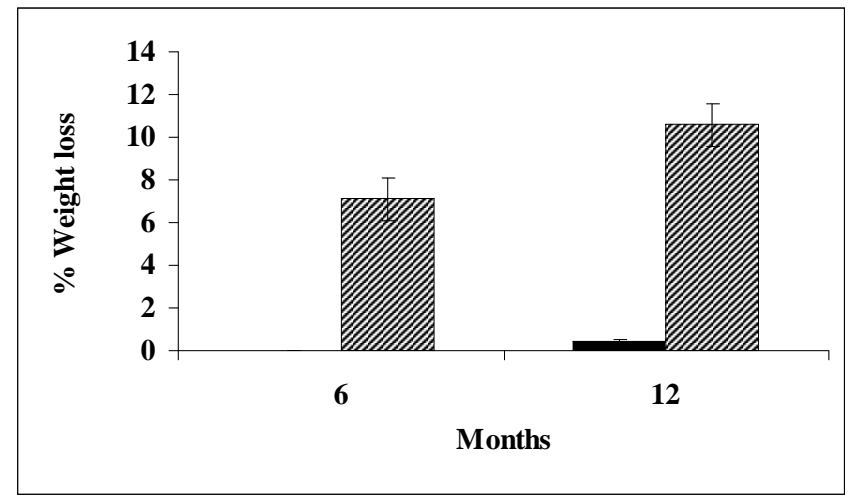

Fig. (8). Comparison of percentage weight loss between unpretreated $(\square)$ and thermally pretreated ( $\mathbb{G}$ ) Polypropylene in 6 and 12 months [37].

\subsubsection{High-Energy Radiation}

\subsection{Electron Beam Radiation}

Electron-beam radiation is a form of ionising energy that is generally characterised, by its low penetration and high dosage rates. It is a concentrated and highly charged stream of electrons. Electrons may be collimated by holes and slits, and since they are electrically charged, they may be focused and energised by electro-magnetic fields. High energy electrons up to 10 million electron Volts $(\mathrm{MeV})$ can be produced by large scale accelerators. The energy of the electrons impinging on the polymer is absorbed by it; bringing in the required changes to it by way of producing radicals which subsequently as mentioned before can initiate several reactions in the polymer. The energy ( $\mathrm{keV}$ or $\mathrm{MeV}$ ), current $(\mathrm{mA})$ and power $(\mathrm{kW})$ of the acceleration are tuned depending upon the thickness and density of the product to be treated. Irradiated polymeric materials become brittle (deterioration) due to reduction in its molecular weight due to degradation [39]. Other changes that could happen include loss in the chain length of the polymer; decrease in cross linking and modifications in the crystalline domain. This degradation mechanism is accentuated by the presence of air leading to simultaneous oxidation [40]. It should be noted that deterioration is different from biodegradation, the latter leads to the incorporation of functional group in the polymer and the former could be a mechanical change.

Fig. (9) shows the Fourier transform infra-red (FTIR) spectrum of 0 and 5 Mrad electron beam irradiated samples of polypropylene (50 micron thickness). The irradiated sample shows an increase in the carbonyl peak at $1715 \mathrm{~cm}^{-1}$ region. The incorporation of this carbonyl could initiate the biodegradation process. The intensity of this peak increases with increases in dosage level.

\subsection{Gamma Radiation}

Gamma rays are an energetic form of electromagnetic radiation produced by radioactive decay of nucleii. They have the highest frequency and highest amount of energy with shortest wavelength out of all the waves in the electromagnetic spectrum. The wavelength range lies in between $10^{-11}$ to $10^{-14} \mathrm{~m}$. Gamma radiation can facilitate the biodegradation of polymer. Studies on the effect of gamma radiation on

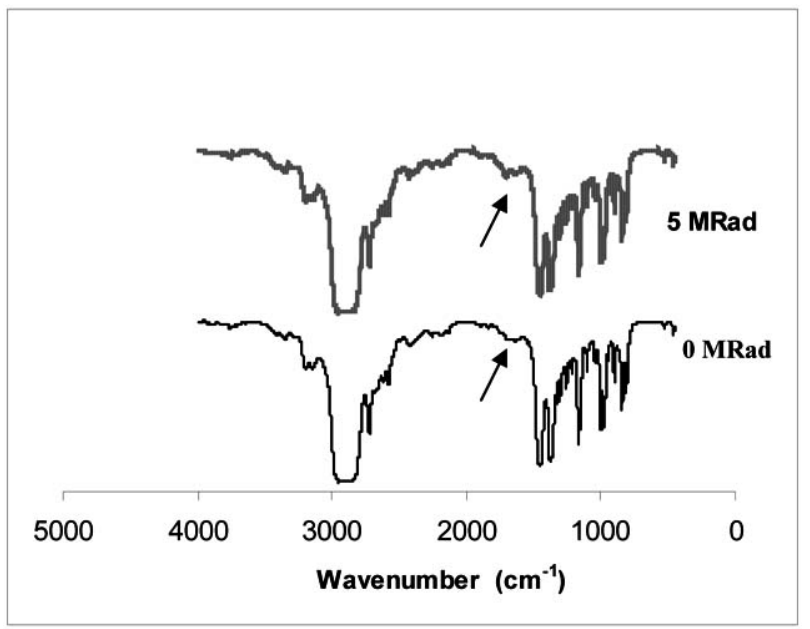

Fig. (9). Comparison of Fourier transform infra-red spectrum of Polypropylene before and after electron beam irradiation. (Arrow indicates the carbonyl region) (Unpublished data).

polypropylene have found that small irradiation dose is enough to significantly enhance the pyrolysis activity [41]. Solvent extractable low volatile radiolysis products of different packaging material and polyolefins after gamma irradiation increased and it was attributed to oxidative decomposition of the polymer, oligomers and additives. Gamma irradiation leads to change in mechanical and electrical properties of PP [42]. These changes are not due to the attack of microorganism. Oxidation can take place after gamma irradiation, which can make the polymer more potent to microbial attack, due to decrease in its hydrophobicity.

\subsubsection{Chemical}

Chemicals can affect the strength, flexibility, surface appearance, colour, dimensions or weight of plastics. Chemicals can attack the polymer in the following ways

1. Attack the chain resulting in the reduction in its physical properties.

2. React or oxidise the functional groups in or on the chain. Depolymerisation can also take place during this process.

3. Form radicals.

4. Bring out physical changes, including absorption of solvents; change its strength, electrical properties, colour, etc., resulting in softening and swelling of the plastic.

5. Allow solvent to permeate through the plastic leading to its dissolution, and

6. Develop stress-cracking due to the interaction of a "stress-cracking agent" with molded-in or external stresses.

Polypropylene is resistant to all the acids and bases in dilute concentration at room temperature. Sulphuric, nitric, and chromic acid $\left(\mathrm{CrO}_{3}+\mathrm{H}_{2} \mathrm{O}\right)$ oxidise PP. Hydrochloric acid treatment of polypropylene changes the color from light to dark brown depending upon the concentration of the acid and the reaction temperature. This is due to the reaction be- 


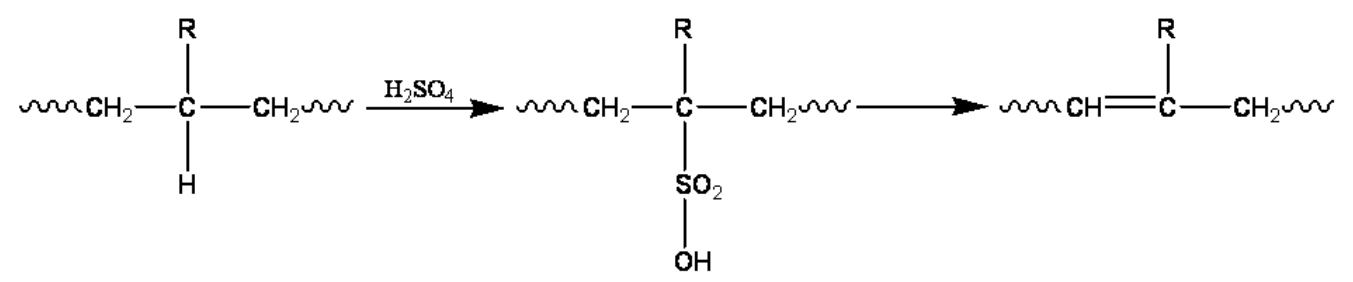

Fig. (10). General mechanism of action of sulphuric acid on polyolefins [44].

tween $\mathrm{HCl}$ with the stabilisers added to the polymer. PP does not show any effect after sulphuric acid treatment up to a concentration of $70 \%$. However, with $80 \%$ sulphuric acid, a decrease in its weight and tensile strength is observed [43]. The acid attacks the amorphous regions of the polymer and forms cracks on the surface.

An increase in sulphuric acid concentration to $98 \%$ over a 75 days treatment period at $100^{\circ} \mathrm{C}$, leads to $80 \%$ decrease in the tensile strength of the polymer. However, when the temperature is reduced to $60^{\circ} \mathrm{C}$ no damage in $\mathrm{PP}$ is observed [43]. The following (Fig. 10) chain reaction is proposed during the oxidative degradation of PP by sulphuric acid in the liquid phase and the same reactions are observed with LDPE and HDPE as well [37, 44]. (Please insert Fig. 10) This mechanism is termed as sulphonation-desulphonation which leads to the dehydrogenation and ultimately to charring of the polypropylene. The FTIR data of LDPE, HDPE and PP after acid treatment show negative peak at $1740 \mathrm{~cm}^{-1}$ indicating that sulphuric acid attacks and destroys carbonyl impurities. FTIR of LDPE treated with sulphuric acid shows the formation of vinylidene unsaturation in the polymer [44]. Polypropylene did not show any change in tensile strength and weight loss when treated with $0-60 \%$ acetic acid at $100^{\circ} \mathrm{C}$. However, with $70 \%$ acetic acid, a drop in strength is observed. PP treated with nitric acid at various concentrations $(10-40 \%)$ and temperature $\left(20-100{ }^{\circ} \mathrm{C}\right)$ showed that at $100^{\circ} \mathrm{C}$ its strength decreased considerably, while the weight loss remained unchanged [43]. The amorphous part of the polymer is oxidised by nitric acid after penetrating into it, while the crystalline portion remains intact. It is stable at low concentration of nitric acid (up to $60{ }^{\circ} \mathrm{C}$ ); but breaks down completely with in the course of a few days at concentration above $10 \%$ at $100^{\circ} \mathrm{C}$. Chromic acid treatment fails to bring about any significant change to polypropylene. It appears to attack the crystalline and amorphous regions at approximately the same rate, thereby removing layers of the polymer uniformly and revealing the microstructure of the interior [43].

\subsection{MICROBES AND MICROBIAL PRODUCTS}

\subsubsection{Enzymatic Degradation}

Oxidative degradation is the main mechanism (Fig. 1) for non-hydrolysable polymers such as polyethylene and polypropylene [16], which leads to reduction in their molecular weight. Oxidative enzymes which include peroxidase, monooxygenase, manganese peroxidaseoxidase and dehydrogenase are responsible for the oxidation of ethylenic groups. These extracellular or intracellular enzymes convert the polymer into monomer, dimmer or oligomers which can enter the microbial cell and then be utilized as the energy source.

Bacteria can use diverse carbon sources as catabolites. The enzymes for metabolising these different substrates can be provided in two ways. A bacterium could constantly synthesis all of the enzymes required for degradation or else could activate enzyme synthesis as necessary to metabolise when needed or is thermodynamically favourable. The manganese peroxidase and lignin degrading enzyme partially purified from Phanerochaete chrysosporium are reported to degrade high molecular weight polyethylene [14, 45].

\subsubsection{Biosurfactant}

Biosurfactants are surface-active compounds produced on microbial cell surface or secreted out by the microorganisms. They are amphiphiles having both hydrophilic and hydrophobic groups, which reduce the interfacial tension at the surface of the liquid or at the interface of two immiscible liquids. They increase the solubility, bioavailability, and biodegradation of hydrophobic or insoluble organic compounds. In addition, biosurfactants play an essential role in the swarming motility of microorganisms, biofilm (either inhibit or accelerate) formation and can complex with heavy metals aiding its removal. Some of the biosurfactants also show antimicrobial activity [46].

\subsubsection{Microbial Surface Active Compounds can be Clas- sified as [46, 47$]$}

1. Low molecular weight biosurfactants including

Glycolipids, lipopeptides, phospholipids, eg., rhamnolipids, Surfactin, viscosin, polymixin etc.,

2. High molecular weight biosurfactants namely

a. Amphiphilic polymer - High molecular weight surface active polymer with hydrophobic region at one end of the molecule, eg., lipopolysaccharides, lipoteichoicacids, lipoglycans etc.,

b. Polyphilic polymers - High molecular weight surface active polymers with hydrophobic groups distributed across the entire molecule, eg. emulsan, alasan, biodispersan, hydrophobic polysaccharides etc.,

\subsubsection{Types of Biosurfactants Produced by Microorgan-} $\underline{\text { isms }}$

Table 1 lists the different types of biosurfactants produced by various microorganisms [48, 49] (including Pseudomonas aeruginosa, Rhodococcus. erythropolis, Nocardia erythropolis, Mycobacterium sp., Torulopsis bombicola, Torulopsis apicola, Torulopsis petrophilum, Ustilago zeae, 


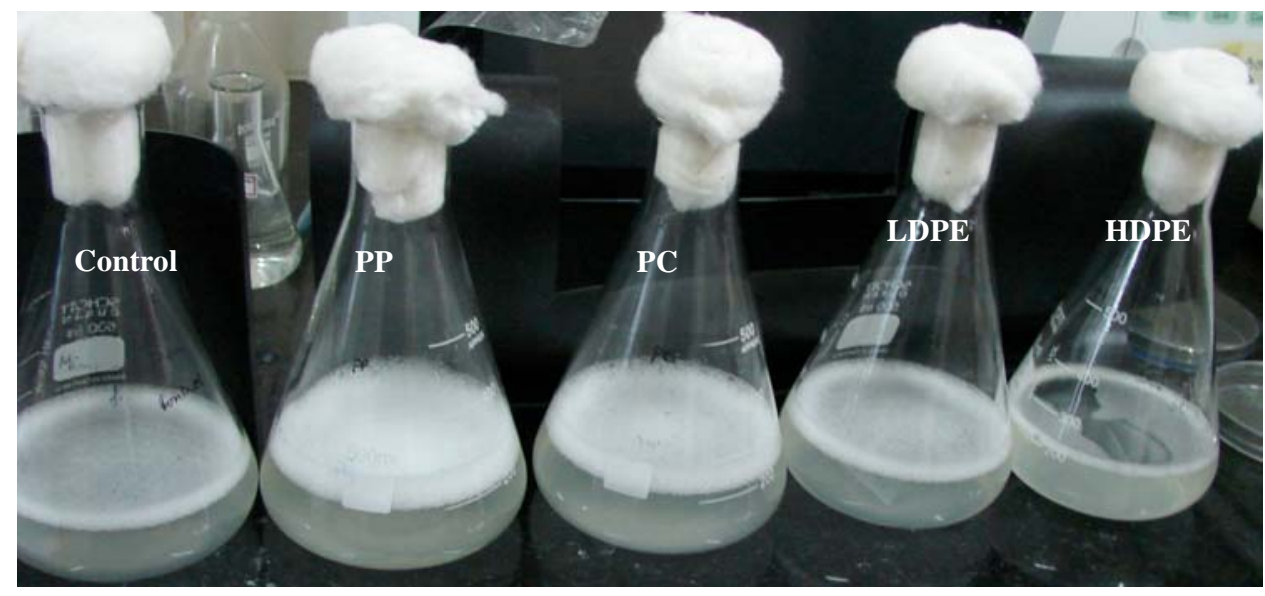

Fig. (11). Production of biosurfactant in the presence of various polymers. (Polypropylene -PP, Polycarbonate - PC, Low Density Polyethylene- LDPE and High Density Polyethylene - HDPE) (Unpublished data).

Table 1. Types of Biosurfactant Produced by Different Microorganisms

\begin{tabular}{|l|l|}
\hline \multicolumn{1}{|c|}{ Types of Biosurfactants Produced } & \multicolumn{1}{c|}{ Microorganisms } \\
\hline \hline $\begin{array}{l}\text { Glycolipids } \\
\text { ( Rhamnolipids, Mannnosylerythritol lipids (MEL), Cellobiolipids, }\end{array}$ & $\begin{array}{l}\text { Pseudomonas aeruginosa, Rhodococcus erythropolis, Nocardia erythropolis, } \\
\text { Mycobacterium sp., Torulopsis bombicola, Torulopsis apicola, Torulopsis } \\
\text { petrophilum, Ustilago zeae, Ustilago maydis. }\end{array}$ \\
$\begin{array}{l}\text { Lipopeptides and lipoproteins } \\
\text { Surfactin, Arthrofactin, Ptisolvin, Viscosinamide etc.,) }\end{array}$ & $\begin{array}{l}\text { Bacillus licheniformis, Serratia marcescens, Pseudomonas fluorescens, Bacil- } \\
\text { lus subtilis, Bacillus brevis, Bacillus polymyxa, }\end{array}$ \\
$\begin{array}{l}\text { Fatty acids, neutral lipids and phospholipids } \\
\text { Polymeric surfactants }\end{array}$ & $\begin{array}{l}\text { Corynebacteriumr lepus, Nocardia erythropolis, Thiobacillus thiooxidans } \\
\text { monas fluorescens, Debaryomyces polymorphis, Pseudomonas aeruginosa }\end{array}$ \\
Particulate biosurfactant & Acinetobacter calcoaceticus and variety of bacteria. \\
\hline
\end{tabular}

Ustilago maydis, Bacillus licheniformis, Serratia marcescens, Pseudomonas fluorescens, Bacillus subtilis, Bacillus brevis, Bacillus polymyxa). A single microorganism can produce many different types of biosurfactants. For example different strains or same strains of Bacillus subtilis can produce different lipopetide biosurfactants which includes surfactin, iturin, esperin, fengycin, mycosubtilin, bacillomycin, subtilisin, plipastatin and bacillopeptin. These lipopeptides have different lipid chain length and may have different aminoacid sequences.

\subsubsection{Role of Biosurfactant in Biodegradation of Poly- olefins}

Polyethylene and polypropylene have $\mathrm{CH}_{2}$ groups and hence are hydrophobic, which is one of the reasons responsible for their inertness to microbial attack. The prerequisite for the biodegradation of polymers is the attachment of microorganisms to the surface or formation of biofilm (complex aggregation of microorganisms and exopolysaccahrids) on the polymer surface. It is reported that this biofilm formation and thus the rate of biodegradation is enhanced by the external addition of synthetic surfactants like Tween $60 / 80$ [31].

Amphiphilic nature of biosurfactant is responsible for the attachment of microorganisms on hydrophobic surfaces. Microorganisms that include Serratia marcescens, Pseudomonas aeruginosa, Bacillus pumilus, Bacillus laterosporus, Acinetobacter calcoaceticus, Escherichia coli and Staphylococcus aureus have surface hydrobhobicity which have a direct correlation with the production of biosurfactant [50].

Colonisation, biofilm formation and biodegradation of polyethylene by Rhodococcus rubber is found to depend strongly on the surface hydrophobicity of the cell. An $8 \%$ weight loss is seen on polyethylene treated with this microorganism within 30 days of incubation [51]. Fig. (11) shows biosurfactant production in the presence of various synthetic polymers such as PP, LDPE, HDPE, and Polycarbonate (PC). The amount of biosurfactant produced is a function of the hydrophobicity of the polymer film. The control flask had no polymer. Flasks containing PP and PC produce maximum amount of biosurfactant when compared to low 


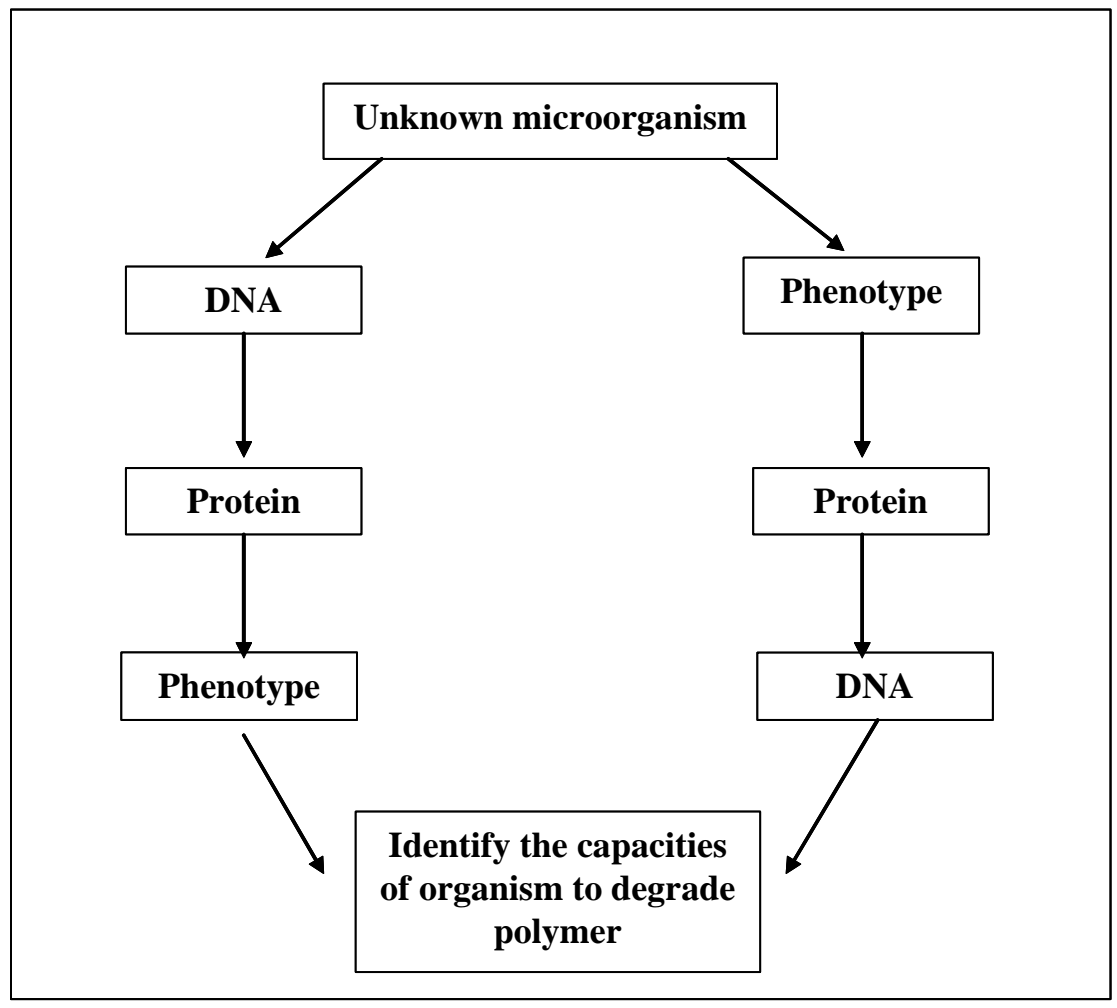

Fig. (12). Parallel pathways which can be followed for genetically engineering microorganisms.

and high density polyethylenes. The contact angle of the polymers PP, PC, LDPE and HDPE are 110, 80, 90 and 73 respectively. PP is the most hydrophobic and HDPE is the most hydrophilic in this sample set. This study is carried out in our lab.

\subsubsection{Factors Affecting Biosurfactant Production}

The amount of biosurfactant produced depends primarily on the microbial source and other factors as listed below [52].

1. Carbon source (glucose, sucrose, glycerol, mollases)

2. Nitrogen source $\left(\mathrm{KNO}_{3}, \mathrm{NH}_{4} \mathrm{NO}_{3}\right.$, urea)

3. addition of hydrocarbon (Vegetable oil like soybean oil, olive oil, castor, sunflower, hexadecane etc.,)

4. addition of salts (Ionic strength $-\mathrm{NaCl}$ upto $5 \mathrm{M}$ ))

5. addition of aminoacids (Leucine, glutamate, valine depends upon the compostion of peptide portion of biosurfactant)

6. addition of metal cations $\left(\mathrm{Ca}^{2+}, \mathrm{Fe}^{2+}, \mathrm{Mn}^{2+}\right.$ - upto 1.4 $\mathrm{X} 10^{-2}$ )

7. $\mathrm{pH}(4.5-10.5$ for Bacillus subtilis $)$

8. Temperature $\left(45^{\circ} \mathrm{C}\right.$ for Bacillus subtilis, $30^{\circ} \mathrm{C}-37^{\circ} \mathrm{C}$ Pseudomonas aeuroginosa $\mathrm{J} 4)$.

9. Agitation (200 rpm is optimum for Pseudomonas aeuroginosa $\mathrm{J} 4$ ), aeration rate and removal of product from the culture (Bacillus subtilis).
The composition of the biosurfactant varies depending upon the carbon, nitrogen, amino acid sources and the medium composition.

\subsubsection{Mixed Culture}

Mixed culture can be more useful than single culture, and when they grow in symbiosis they may enhance the growth of the biofilm formed as well as increase the hydropillicity of the polymer surface when compared to growth of individual organism which may ultimately makes the polymer more susceptible to degradation. Microbial culture like Klebsiella pneumonia and Pseudomonas aeruginosa are reported to form a biofilm on the surface of steel. The later colonises the surface faster while the former grows faster on the surface layer of this biofilm [53]. Mixed spore culture of four fungi (Aspergillus niger, Penicillium funiculosum, Paecilomyces variotii and Gliocladium virens) are reported to grow on thermally oxidised PE having cobalt as, prooxidant in solid agar for many weeks. The molecular weight of the polymer decreased with respect to increase in the fungal growth on the films. Gel permeation chromatography (GPC) showed that the low molecular weight fragments generated during abiotic oxidation of PE were eliminated in the presence of fungi [54]. Mixed culture of fungus and bacteria, (Penicillum frequents and Bacillus mycoides) was found to grow on degradable polyethylene (having chemical and photo intiators). The mixed culture reduced the weight of the polymer by $7 \%$ whereas single culture of the same microorganism showed $0.50 \%$ reduction in weight, indicating a synergy between the two microorganisms leading to 14 - times increase in the biodegradability of the polymer [55]. 


\section{GENETIC ENGINEERING}

Once the biodegradation pathway is well established the organism could be genetically modified so that the desired enzyme is made to be secreted more or, the process could be directed to follow a specific pathway. The main drawback of biodegradation process is that the polymer takes longer time to degrade. Reducing the time period required for biodegradation can be achieved by either making the polymer more susceptible to microbial attack (which was discussed in the earlier section) or by enhancing the capability of the microorganism to degrade the polymer (Genetic engineering). The latter possibility can be attempted by utilising genetic engineering tools including DNA sequencing, protein sequencing, production of recombinant organism, etc. Biosynthetic genes phbA (for 3-ketothiolase), phbB (NADPH-dependent acetoacetyl-CoA reductase), and phbC (PHB synthase) from acetyl-CoA have been cloned to produce polyhydroxyalkanoic acid (PHA) and poly (3-hidroxybutyric acid) (PHB) [56]. These genes are clustered and are presumably organised in one operon. The genes have been expressed in Escherichia coli and in different species of the genus Pseudomonas.

Genetic engineering makes it possible to alter the properties of the existing degradative enzymes, to modify regulatory mechanisms and to assemble within single organism degradative enzymes from phylogenetically distant organisms. Uncovering new genes with unknown functions provides new clues about the richness of microbial genetic diversity and gives us the pool from which novel biocatalysts (enzymes) can be isolated. New types of biochemical reactions (by enzymes) will not be discovered by DNA sequence analysis alone. Both reaction and gene screening need to occur in parallel.

In this process, after gene sequences are obtained, similarities to known gene product (mostly proteins) are deduced, and the biological functions, phenotypes are suggested. In this way, genes are used to deduce what a bacterium can or cannot do. The identification of similarity between unknown and known sequences reported in data bases are done using bioinformatics tools. This study will map the sequence of the new organism with the one whose biological function has been well established by a variety of computational methods. In this way, with the help of chemical experiments and sequencing the genes, one would be able to understand the capability of a particular bacterium. Two pathways that can be attempted to genetically improve the biodegradation capability of the organism are shown in Fig. (12). (Please insert Fig. 12). The first approach involves starting directly from the DNA sequencing data and to deduce the protein sequence from this information. Subsequently the function of the protein is deduced. In the second approach the functional genomics is reversed. In this approach discovery flows from phenotype to protein to gene (DNA) [57].

\section{FUTURE TRENDS}

In the natural environment, different kinds of microorganisms play an important role in various steps involved in the degradation of synthetic polymers in general, and polyolefins in particular. Studying the synergism between those microorganisms will give insight for future efforts towards the biodegradation of these materials. Polyolefins with only methylene repeat units are highly recalcitrant, have high molecular weight, and have hydrophobic surfaces making them difficult for the microorganism to form stable biofilms and degrade them to small molecular weight oligomers.

An understanding of the degradation mechanisms of both natural and synthetic polymers by microorganisms and enzymes will open up new prospects in the field of biodegradable plastics and also address the other environmental issues. The biodegradation mechanisms of the polymeric material will contribute to further development of the next generation materials having a high environmental acceptability and recyclability. If one can utilise these polyolefin wastes to produce some useful products like biosurfactant, the biodegradation process will be economically favourable. Use of biosurfactant producing organisms has not been fully exploited in the use of polymer degradation. In addition to screening soil microorganisms, isolating microorganisms from marine, petroleum waste and polymer dump site could lead to new unexplored strains, with superior performance. Polymer degradation and transformation technologies are also essential for polymer production and recycling. Polyethylene and polypropylene can be synthesised and chemically recycled by novel enzyme - catalysed polymerisation and degradation methods.

If one can characterise the genes responsible for the production of degrading enzymes and its regulation by using current genetic engineering tools, one can genetically modify the microorganisms and use them as a superbug for degrading the recalcitrant polyolefins. Genomics and proteomics could speed up the above mentioned step and hence more research should be focused in this direction.

In the world of Bioinformatics and Biostatistics mathematical simulation of polymer degradation process can be the future area of interest. The algorithms of the chain scission mechanism which can be induced by any physical treatment on the polymer like exposure to UV, $\gamma$, ionising radiation; thermal; chemical; or mechanical stimuli has been established [58]. This study can help us to develop special recycling techniques, biotic environment required to achieve biodegradation, and degradation tenure of polymer. Algorithms are developed for the degradation of linear and branched polymers. All these models are based on either some statistical approximations or developed based on the kinetics of degradation process [59-61].

Computational and molecular modelling techniques in spite of their widespread use in materials science, medicinal chemistry and the pharmaceutical sciences, has not been attempted in the area of environmental sciences. With the continued increase in computer power, it is hoped that one day it may be possible to predict the static and dynamic biological response of microorganisms such as bacteria and fungi when they come in contact with a polymeric surface, the formation of biofilms and generation of extracellular enzymes and polysaccharides. It should be possible to simulate the dynamic growth of a biofilm on a polymer surface and the population of various biological species in the biofilm. 


\section{REFERENCES}

[1] I. Jakubowicz, "Evaluation of degradability of biodegradable polyethylene (PE)", Polymer Degradation and Stability, vol. 80, pp. 3943, 2003.

[2] L. Sharma, and N. Mallick, "Accumulation of poly- $\beta$ hydroxybutyrate in Nostoc muscorum: regulation by $\mathrm{pH}$, light-dark cycles, $\mathrm{N}$ and $\mathrm{P}$ status and carbon sources", Bioresource Technology, vol 96, pp. 1304-1310, 2005.

[3] I. Gilan, Y. Hadar, and A. Sivan, "Colonisation, biofilm formation and biodegradation of polyethylene by a strain of Rhodococcus ruber", Applied Microbiology and Biotechnology, vol. 65, pp. 97104, 2004.

[4] A. Sivan, M. Szanto, and V. Pavlov, "Biofilm of development of polyethylene degrading bacterium Rhodococcus ruber", Applied Microbiology and Biotechnology, vol. 76, pp. 346-352, 2006.

[5] J. Arutchelvi, M. Sudhakar, A. Arkatkar, M. Doble, S. Bhaduri, and P. V. Uppara, "Biodegradation of polyethylene and polypropylene", Indian Journal of Biotechnology, vol. 7, pp. 9-22, 2008.

[6] A. Davis and D. Sims, "Photooxidation and stabilisation", in Weathering of polymers, UK: Spinger, 1983, pp. 112-120.

[7] A-C. Albertson, C. Barenstedt, S. Karlsson, and T. Lindberg, "Degradation product pattern and morphology changes as means to differentiate abiotically and biotically aged degradable polyethylene", Polymer, vol. 36, pp. 3075-3083, 1995.

[8] A-C. Albertsson, and S. Karlsson, "The influence of Biotic and Abiotic environments on the degradation of polyethylene", Progress in Polymer Science, vol. 15, pp. 177-192, 1990.

[9] A-C. Albertsson, "Biodegradation of synthetic polymers. II: a limited microbial conversion of ${ }^{14} \mathrm{C}$ in polyethylene to ${ }^{14} \mathrm{CO}_{2}$ by some soil fungi", Journal of Applied Polymer Science, vol. 22, pp. 3419-3433, 2003.

[10] F. Khabbaz, A-C. Albertsson, and S. Karlsson, "Chemical and morphological changes of environmentally degradable poly (ethylene) films exposed to thermo-oxidation", Polymer Degradation and Stability, vol. 63, pp. 127-138, 1999.

[11] A-C. Albertson, S. O. Andersson, and S. Karlsson, "The mechanism of biodegradation of polyethylene", Polymer degradation and stability, vol. 18, pp. 73-87, 1987.

[12] M. Sudhakar, A. Trishul, M. Doble, K. S. Kumar, S. S. Jahan, D. Inbakandan, R.R. Viduthalai, V.R. Umadevi, P. S. Murthy, and R. Venkatesan, "Biofouling and biodegradation of polyolefins in ocean waters", Polymer Degradation and Stability, vol. 92, pp. 1743-1752, 2007.

[13] F. Severini, R. Gallo, and S. Ipsale, "Environmental degradation of polypropylene", Polymer Degradation and Stability, vol. 22, pp. 185-194, 1988.

[14] M. Shimao, "Biodegradation of plastics", Current Opinion in Biotechnology, vol. 12, pp. 242-247, 2001.

[15] J-D. Gu, "Microbiological deterioration and degradation of synthetic polymeric", International Biodeterioration \& Biodegradation, vol. 52, pp. 69-91, 2003.

[16] A.A. Shah, F. Hasan, A. Hameed, and S. Ahmed, "Biological degradation of plastics: a comprehensive review", Biotechnology Advances, vol. 26, pp. 246-265, 2008.

[17] P. Raj, and M. Doble, "Biodegradation of polymers", Indian Journal of Biotechnology, vol. 4, pp. 186-193, 2005.

[18] C. Vasile, "Degradation and decomposition", in Handbook of Polyolefins synthesis and properties, C. Vasile, and R. B. Seymour, Eds. New York: Marcel Dekker Inc, 1993, pp. 479-506.

[19] E. Chiellini, A. Corti, and G.Swift, "Biodegradation of thermallyoxidized, fragmented low density polyethylene", Polymer Degradation Stability, vol. 81, pp. 341-351, 2003.

[20] X. Ramis, A. Cadenato, J. M. Salla, J. M. Morancho, A. Valles, L. Contat, and A. Ribes, "Thermal degradation of polypropylene/starch based materials with enhanced biodegradability", Polymer Degradation and Stability, vol. 86, pp. 483-491, 2004.

[21] D. Oldak, and H. Kaczmarek, "Photo- and bio-degradation processes in polyethylene, cellulose and their blends studied by ATRFTIR and Raman spectroscopies”, Journal of Materials Science, vol. 40, pp. 4189-4198, 2005.

[22] M. Rutkowska, A. Heimowska, K. Krasowska, and H. Janik, "Biodegradability of polyethylene starch blends in sea water", Polish Journal of Environmental Science, vol. 11, pp. 267-274, 2002.

[23] K. E. Johnson, A. L. Pometto III, and Z. L. Nikolo, "Degradation of degradable starch-polyethylene plastics in a compost environ- ment", Applied and Environmental Microbiology, vol. 59, pp. 1155-1161, 1993.

[24] H. A. EI-Shafei, N.H.A. EI-Nasser, A.L. Kansoh, and M. Ali, "Biodegradation of disposable polyethylene by fungi and Streptomyces species", Polymer Degradation and Stability, vol. 62, pp. 361-365, 1998 .

[25] M. Mikulasova, B. Kosikova, P. Alexy, F. Kacik, and E. Urgelova, "Effect of blending lignin biopolymer on the biodegradability of polyolefin plastics", World Journal of Microbiology and Biotechnology, vol. 17, pp. 601-607, 2001.

[26] M. Sudhakar, M. Doble, P. S. Murthy, and R. Venkatesan, "Marine microbe-mediated biodegradation of low- and high-density polyethylenes", International Biodeterioration \& Biodegradation, vol, 61, pp. 203-213, 2008.

[27] L. Tilstra, and D. Johnsonbaugh, "The biodegradation of blends of polycaprolactone and polyethylene exposed to a defined consortium of fungi”, Journal of Environmental Polymer Degradation, vol. 1, pp. 257-267, 1993.

[28] A. lwamoto and Y. Tokiwa, "Enzymatic degradation of plastics containing polycaprolactone", Polymer Degradation and Stability, vol. 45, pp. 205-213, 1994.

[29] M. Koutny, J. Lemaire, and A-M. Delort, "Biodegradation of polyethylene films with prooxidant additives", Chemosphere, vol. 64 , pp. 1243-1252, 2006.

[30] R. Arnaud, P. Dabin, J. Lemaire, S. Al-Malaika, S. Chohan, M Coker, G. Scott, A. Fauve, and A. Maaroufi, "Photooxidation and biodegradation of commercial photodegradable polyethylenes", Polymer Degradation and Stability, vol. 46, pp. 211-224, 1994.

[31] E. Chiellini, A. Corti, and S. D'Antone, "Oxo-biodegradable full carbon backbone polymers - biodegradation behavior of thermally oxidized polyethylene in an aqueous medium", Polymer Degradation and Stability, vol. 92, pp. 1378-1383, 2007.

[32] E. Chiellini, A. Corti, S. D'Antone, and R. Baciu, "Oxobiodegradable carbon backbone polymers - oxidative degradation of polyethylene under accelerated test conditions", Polymer Degradation and Stability, vol. 91, pp. 2739-2747, 2006.

[33] M. Koutny, M. Sancelme, C. Dabin, N. Pichon, A-M. Delort, and J. Lemaire, "Acquired biodegradability of polyethylenes containing pro-oxidant additives", Polymer Degradation and Stability, vol. 91, pp. $1495-1503,2006$.

[34] A.C. Albertsson, C. Sares, and S. Karlsson, "Increased biodegradation of LDPE with nonionic surfactants", Acta Polymerica, vol. 44, pp. 243-246, 1993.

[35] D. Hadad, S. Geresh, and A. Sivan, "Biodegradation of polyethylene by the thermophillic bacterium Brevibacillus borstelensis", Journal of Applied Microbiology, vol. 98, pp. 1093-1100, 2005.

[36] K .Y. Onodera, H. Mukumoto, Y. Katsuyaya, A. Saiganji, and Y Tani, "Degradation of polyethylene by a fungus Penicillium simplicissimum YK", Polymer Degradation and Stability, vol. 72, pp. 323-327, 2001.

[37] A. Arkatkar, J. Arutchelvi, S. Bhaduri, P. V. Uppara, and M. Doble, "Degradation of unpretreated and thermally pretreated polypropylene by soil consortia", International Biodeterioration \& Biodegradation, vol. 63, pp. 106-111, 2009.

[38] T. V-Sepulveda, E. F-Torres, A. M-Guzman, M. L-Gonzalez, and G. T-Quintero, "Microbial degradation of thermo-oxidized low density polyethylene", Journal of Applied Polymer Science, vol. 73, pp. 1435-1440, 1999.

[39] F. Yoshii, G. Meligiz, T. Sasaki, K. Makuuchi, A. M. Rabie, and S. Nishimoto, "Effect of irradiation on the degradability of polypropylene in the natural environment", Polymer Degradation and Stability, vol. 49, pp. 315-321, 1995.

[40] S. Kawanishi, Y. Shimizu, S. Sugimoto, and S. Nobutake, "Iradiation effects of excimer laser radiation and electron beam on polypropylene and ethylene-tetrafluroethylene copolymer films", Polymer, vol. 32, pp. 979-983, 1991.

[41] A. Dawood and M. Kovichi, "Pyrolysis kinetics of $\gamma$-irradiated polypropylene", Polymer degradation and stability, vol. 73, pp. 347-354, 2001

[42] P.G. Demertzis, R. Franz, and F. Welle, "The effect of $\gamma$-irradiation on compositional changes in plastic packaging films", Packaging Technology and Science, vol. 12, pp. 119-130, 1991.

[43] M. Volcheck, A. V. Goryainova, and I.Y. Klinov, "Chemical stability of polypropylene", Chemical and Petroleum Engineering, vol. 4, pp. 911-914, 1968. 
[44] G. G. Cameron, and B. R. Main, "The action of concentrated sulphuric acid on polyethylene and polypropylene: part I - Evolution of sulphur dioxide and carbon dioxide", Polymer degradation and stability, vol. 5, pp. 215-225, 1983.

[45] Y. Iiyoshi, Y. Tsutsumi, and T. Nishida, "Polyethylene degradation by lignin-degrading fungi and manganese peroxidase", Journal of Wood Science, vol. 44, pp. 222-229, 1998.

[46] J. D. Van Hamme, A. Singh, and O. P. Ward, "Physiological aspects Part 1 in a series of papers devoted to surfactant in microbiology and biotechnology", Biotechnology Advances, vol. 24, pp. 604620, 2006.

[47] T. R. Neu, "Significance of Bacterial surface active compounds in interaction of bacteria with interfaces", Microbiological Reviews, vol. 60 , pp. 151-166, 1996.

[48] J. D. Desai, and I. M. Banat, "Microbial production of surfactants and their commercial potential", Microbiology and Molecular biology reviews, vol. 61, pp. 47-64, 1971.

[49] J. I. Arutchelvi, S. Bhaduri, P.V. Uppara, and M. Doble, "Mannosylerythritol lipids: a review", Journal of Industrial Microbiology and Biotechnology, 2008, doi 10.1007/s10295-008-0460-4.

[50] V. Pruthi, and S.S. Cameotra, "Rapid identification of biosurfactantproducing bacterial strains using a cell surface hydrophobicity technique", Biotechnology Techniques, vol. 11, pp. 671-674, 1997.

[51] I. Gilan, Y. Hadar, and A. Sivan, "Colonization, biofilm formation and biodegradation of polyethylene by a strain of Rhodococcus rubber", Applied Microbiology and Biotechnology, vol. 65, pp. 97104, 2004.

[52] D. G. Cooper, R. Macdonald, S. J. B. Duff, and N. Kosaric, "Enhanced production of surfactin from Bacillus subtilis by continuous product removal and metal cation addition", Applied and Environmental microbiology, vol. 42, pp. 408-412, 1981.
[53] P.S. Stewart, A.K. Camper, S.D. Handran, C-T. Huang, and M. Warnecke, "Spatial distribution and coexistence of Klebsiella pneumoniae and Pseudomonas aeruginosa in Biofilms", Microbial Ecology, vol. 33, pp. 2-10, 1997.

[54] M. Weiland, A. Daro, and C. David, "Biodegradation of thermally oxidized polyethylene", Polymer Degradation and Stability, vol. 48, pp. 275-289, 1995

[55] G. Seneviratne, N. S. Tennakoon, M. L. M. A. W. Weerasekara, and K. A. Nandasena, "Polyethylene biodegradation by a developed Penicillium-Bacillus biofilms", Current Science, vol. 90, pp. 20-21, 2006.

[56] S. C. Slater, W. H. Voige, and D. E. Dennis, "Cloning and expression in Escherichia coli of the Alcaligenes eutrophus H 16 Poly- $\beta$ hydroxybutyrate biosynthesis pathway", Journal of bacteriology, vol. 170, pp. 4431-44436, 1988 .

[57] L. P. Wackett, and C. D. Hershberg, Biocatalysis and Biodegradation; Microbiol Transformation of Organic Compounds. Washington: ASM Press, 2001

[58] H. Galina, and J. Lechowicz, "An algorithm for Monte Carlo modeling of degradation of polymer networks", Computers and Chemistry, vol. 22, pp. 39-41, 1998.

[59] M. Emsley, and R. J. Heywood, "Computer modelling of the degradation of linear polymers", Polymer Degradation and Stability, vol. 49, pp. 145-149, 1995.

[60] H. Galina, and J. B. Lechowicz, "Monte Carlo modelling of degradation of polymer networks", Polymer Gels and Networks, vol.6, pp. 103-111, 1998

[61] H. Galina, and J. B. Lechowicz, "Monte Carlo modelling of degradation of polymer networks: 2. Highly branched molecules", Polymer Gels and Networks, vol. 6, pp. 247-255, 1998.

(C) Arkatkar et al.; Licensee Bentham Open.

This is an open access article licensed under the terms of the Creative Commons Attribution Non-Commercial License (http://creativecommons.org/licenses/by-nc/3.0/) which permits unrestricted, non-commercial use, distribution and reproduction in any medium, provided the work is properly cited. 